\title{
Induced spawning of red drum, Sciaenops ocellatus: use of multivariate and univariate analysis methods in the search for side effects of LH-RHa treatments and ovarian development state upon spawn quality
}

\author{
Lionel Gardes ${ }^{(\mathrm{a} *)}$, Philippe Villanove ${ }^{(\mathrm{a})}$, Vincent Buchet ${ }^{(\mathrm{a})}$, Christian Fauvel ${ }^{\left(\mathrm{b}^{*}\right)}$ \\ (a) Laboratoire ressources aquacoles, Institut français pour l'exploitation de la mer, Pointe Fort, 97231 Le Robert Martinique, France \\ (b) Station expérimentale d'aquaculture, Institut français pour l'exploitation de la mer, Chemin de Maguelonne, \\ 34250 Palavas, France
}

Received June 15, 1999; accepted December 2, 1999

\begin{abstract}
The present work examines the usefulness of the combination of multivariate analyses and further one-way analysis of variance in the search for links between causes and effects in heterologous stimulation of spawning in fish. Stimulations with both 20 and $50 \mu \mathrm{g} \cdot \mathrm{kg}^{-1}$ doses of [D Trp $\left.{ }^{6}\right]$ luteinizing hormone-releasing hormone analogue (LH-RHa) were effective in inducing and synchronizing spawning of red drum, Sciaenops ocellatus. Oocyte development monitoring using ovarian biopsy allowed treatment injections at different stages of maturation. The influence at stimulation time of female oocyte development state upon further development was shown. An interesting potential of second stimulation, leading to high quality spawns, was established and factors of success were identified. The best conditions for stimulation success were simultaneously late stage of oocyte development characterized by the beginning of oil droplet coalescence, high ovarian homogeneity quoted by the proportion of most developed oocytes in the biopsy sample, and low dose of hormone $\left(20 \mu \mathrm{g} \cdot \mathrm{kg}^{-1}\right)$ for both first and second stimulations. () 2000 Ifremer/Cnrs/Inra/Ird/Cemagref/Éditions scientifiques et médicales Elsevier SAS
\end{abstract}

Fish culture / induced breeding / LH-RH analogues / multivariate analysis / egg quality / oocyte development / red drum / Sciaenops ocellatus

Résumé - Induction de la ponte chez l'ombrine subtropicale, Sciaenops ocellatus : utilisation de méthodes d'analyses multivariées et univariées pour la recherche d'effets secondaires des traitements à l'hormone LH-RHa et de l'état de développement ovarien sur la qualité des pontes. Ce travail examine l'intérêt de la combinaison d'analyses multivariées et de l'analyse de variance à un facteur pour la recherche de liens au sein d'expérimentations aquacoles faisant intervenir une diversité de causes et d'effets. L'injection de l'analogue [D $\mathrm{Trp}^{6}$ ] de la gonado-libérine (LH-RHa) est efficace aux doses de 20 et $50 \mu \mathrm{g} \cdot \mathrm{kg}^{-1}$ pour provoquer et synchroniser les pontes chez l'ombrine, Sciaenops ocellatus. Un suivi du développement ovocytaire par biopsie ovarienne permet en outre de réaliser des injections à différents stades de maturation et l'influence du stade ovocytaire de la femelle, au moment de la stimulation sur la qualité de la ponte, est ainsi mise en évidence. Un potentiel intéressant suite à une seconde stimulation aboutissant à des pontes de qualité, est établi et des facteurs de réussite sont identifiés. Les meilleures conditions pour le succès de la stimulation sont simultanément : le dernier stade de développement ovocytaire, caractérisé par le début de coalescence de la gouttelette lipidique, la forte homogénéité ovarienne représentant la proportion des ovocytes les plus développés au sein de l'échantillon obtenu par biopsie, la faible dose hormonale $\left(20 \mu \mathrm{g} \cdot \mathrm{kg}^{-1}\right)$ à la fois pour les premières et les secondes stimulations. (C) 2000 Ifremer/Cnrs/Inra/Ird/Cemagref/Éditions scientifiques et médicales Elsevier SAS

Pisciculture / induction de la ponte / LH-RH analogues / analyse multivariée / qualité des oufs / développement ovocytaire / ombrine / Sciaenops ocellatus

\footnotetext{
* Corresponding authors: lgardes@ifremer.fr; cfauvel@ifremer.fr
} 


\section{INTRODUCTION}

Statistical analysis using standard methods (ANOVA, regression, etc.) is inappropriate for simultaneous treatment of data relating to different cause and effect parameters. These methods often fail to extract accurate information, mainly because they cannot account for multifactorial synergistic effects, which are only brought to light by multivariate methods [22]. The use of such methods is traditionally limited to fishery investigations, but as large amounts of data are also generated by aquaculture experiments, multivariate analyses appear to be an interesting method to examine broader issues including genetics, morphology $[4,5]$, growth $[18,20]$ and mortality [14]. In the present study, multivariate analysis was used to attempt to establish relationships between causes (hormonal doses, ovarian state, number of stimulated spawning cycles) and effects (egg quality) in the widely investigated field of heterologous stimulation of fish reproduction.

Whatever the species produced, development of profitable aquaculture is linked to the technical mastery that allows production of large quantities of good quality eggs so as to provide fry throughout the year. Today, red drum, Sciaenops ocellatus, aquaculture in the French West Indies faces this problem. Luteinizing hormone-releasing hormone and its analogues ( $\mathrm{LH}-$ $\mathrm{RHa}$ ) have been used since the end of 1960s to induce spawning in many teleosts $[8,21,28]$. Many of these studies examined separately the influence of different parameters on the quality of spawns obtained following hormonal stimulation [6, 11-13, 27]. Preliminary work on induced spawning of Sciaenids, including red drum, provided successful spawns after injections of 100,50 and $20 \mu \mathrm{g} \cdot \mathrm{kg}^{-1} \mathrm{LH}-\mathrm{RHa}$, but little information was given on reproducibility of the technique, egg, larvae or fry quality [24, 25].

Egg quality, namely the egg's potential to produce viable fry, is affected by both intrinsic (physiological, genetic) properties of the egg itself and extrinsic ones (environment in which they are fertilized and incubated) $[2,15]$. Investigations on egg quality must be based on comparative tests of several parameters [15]. In the present study, egg size, fertilization, hatching, survival to specific development stages as well as survival of starved larvae produced from LH-RHa treatment were tested as quality indices in order to examine for possible side effects of heterologous stimulation according to hormonal dose, oocyte development stage at stimulation time and number of stimulations performed.

\section{MATERIALS AND METHODS}

\subsection{Fish}

Seventeen 3-year-old females (5 $100 \pm 800 \mathrm{~g})$ and 11 males (5300 $\pm 950 \mathrm{~g})$ produced from captive broodstock and out of reproduction season (oocyte

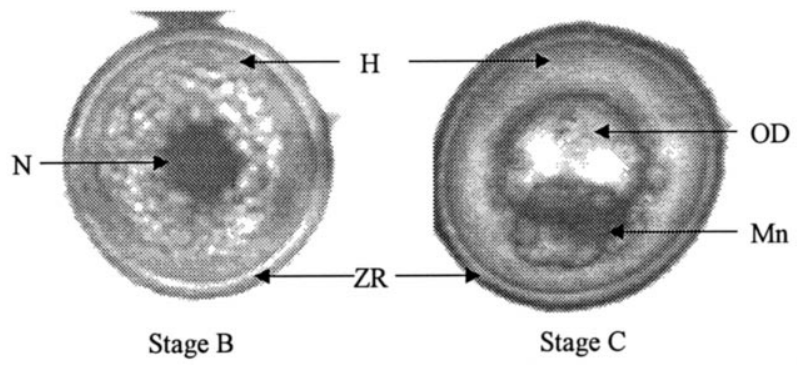

Figure 1. Illustration of the two post-vitellogenic oocyte stages, differing by nucleus position and lipid coalescence completion, chosen for induced spawning experiments in Sciaenops ocellatus (from Fauvel and Suquet [10]). N, nucleus; Mn, migrating nucleus; OD, oil droplet; $\mathrm{H}$; vitellus hyalinization; ZR, zona radiata.

diameter below $100 \mu \mathrm{m}$ in females and lack of available sperm) were subjected to photoperiod and temperature modifications according to Arnold [1] and Roberts [23], so as to induce and complete vitellogenesis in Ifremer West Indies facilities. Fish were reared in a $16-\mathrm{m}^{3}$ tank $\left(24^{\circ} \mathrm{C}\right.$ during experiments $)$ with $60-100 \%$ daily water renewal and fed pellets (Biomar Ecolife 16 no. 12) ad libitum. Rearing density was about $11 \mathrm{~kg} \cdot \mathrm{m}^{-3}$. Fish were always handled after anaesthesia with phenoxy-2 ethanol $(0.3 \%)$. They were identified individually by a PIT tag implanted under the skin.

Oocyte development was monitored by biopsies from the median zone of the ovary. For oocyte development staging according to the state of vitellus, samples were subjected to a flow under pressure (syringe) of clearing fixative (ethanol 6 vols, formol 3 vols, acetic acid 1 vol.) allowing follicle separation and observation of cellular content. Two stages (B and C) were taken into account according to Fauvel and Suquet [10] and Parfouru and Fauvel [19]. They were related to post-vitellogenic stages and differed by nucleus position and lipid coalescence completion (figure 1). Ovarian samples of equal volume were carried out fortnightly during vitellogenesis using a special disposable instrument for human endometer biopsy, then all females were sampled weekly. Diameter, vitellus state (stage) of the most advanced oocytes and the approximate proportion of this stage among all the stages observed in the sample were recorded. This last proportion was evaluated as one of three levels of ovarian homogeneity $(\mathrm{OH})$ defined as follows. Level 1: few oocytes have reached the most advanced stage; level 2: $50 \%$ of oocytes have reached the stage; level 3: most oocytes have reached the stage.

Males were concomitantly checked for sperm release at stripping.

\subsection{Experimental procedure}

Twenty-six treatment injections, of which 17 first and 9 second stimulations, were realized. Stimulations with either $20 \mu \mathrm{g} \cdot \mathrm{kg}^{-1}$ ( $n=14$ first stimulations; $n=6$ second stimulations) or $50 \mu \mathrm{g} \cdot \mathrm{kg}^{-1}$ ( $n=3$ first stimu- 
lations; $n=3$ second stimulations) [D Trp ${ }^{6}$ ] LH-RHa (SIGMA chimie, France) were performed by injection of $1 \mathrm{~mL} \cdot \mathrm{kg}^{-1}$ hormone solution into the intermuscular zone just behind the dorsal fin of females showing stages B $(n=16)$ and C $(n=10)$, each stage and dose being treated in triplicate. Second stimulations were performed with the same dose at least 15 days after the preceding stimulated spawning cycle (first induced spawning) and only when the adequate oocyte stage (B or C) was reached again.

Then, females were placed individually into $2-\mathrm{m}^{3}$ spawning tanks (temperature: $27.8-31.5^{\circ} \mathrm{C}$ and salinity: $33 \%$ ) into which a male had been previously introduced. Spawnings occurred in these conditions, whereas control non-injected females subjected to the same experimental and rearing conditions (biopsy, temperature shock and presence of male) did not spawn.

Eggs of successfully stimulated females were collected at the surface outflow of each tank and triplicates of 1000 were placed in 3.7-L incubators for embryonic development. Samples of newly hatched larvae were allowed to develop in beakers without water renewal or food in order not to introduce unknown extrinsic factors into the analyses and hence to evaluate quality of vitelline reserves.

Quality was assessed for each spawn through time of response to stimulation ( $\mathrm{t}$ ), volume of spawn (Vol), number of eggs laid (Neggs), mean diameter of eggs (MD), fertilization rate (F) defined as fertilized eggs/ total egg number, percentage of eggs with a single oil droplet (\%Oil), hatching rate $(\mathrm{H})$ defined as hatched larvae/fertilized eggs, time of death of all starved larvae (M), mortality rate after 6 days (M6d) and time needed to reach a death level of $50 \%(50 \% \mathrm{M})$ of larvae.

\subsection{Statistical analysis}

Two types of statistical analysis were chosen to study the population of spawns resulting from different combined treatments (dose of hormone, ovarian state, number of stimulated spawning cycles) applied to different females. A multivariate analysis performed on 26 individuals (spawns) and ten quantitative variables described the global structure of the population. This analysis included two complementary methods: a hierarchical ascendant classification (HAC) allowing identification, through the study of test values $[16,26]$, of the different groups that make up the population and their features and a principal component analysis (PCA) permitting comparison of subpopulations characterized by a particular experimental treatment, through the spatial dispersion of their individuals within the whole population upon the factorial plane [9].

One-way analysis of variance (ANOVA) followed by pairwise multiple comparison Student-NewmanKeuls test, finally validated and sharpened multivariate analysis results, by searching for significant differences between subpopulations brought out by previous analyses and by associating confidence intervals to

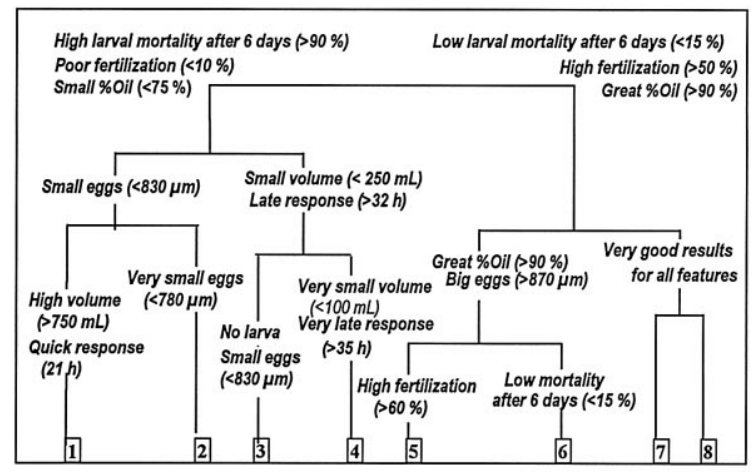

Figure 2. Dendrogram reconstitution following test value study. Synthesis presenting the criteria (spawn features) that have mostly contributed to separation of individual spawns into eight classes.

these differences. The ANOVA fixed model chosen was adapted to the study of unequal strength populations, following the process described by Dagnelie [7].

Multivariate analyses were performed using SPAD 3.5 software.

\section{RESULTS}

\subsection{Population structure}

HAC generated a dendrogram in which eight classes of spawns could be isolated. The population was first divided into two groups of four classes allowing identification of poor (classes 1-4) and high quality (classes 5-8) spawns. Through the study of test values, the variables that contributed most to the drawing up of classes were identified as percentage of eggs with a single oil droplet, egg size, fertilization rate and mortality of 6-day-old larvae. The results of this study were incorporated into the dendrogram (figure 2).

\subsubsection{Factors impacting spawn quality}

Experimental conditions (female characteristics at stimulation time) leading to poor quality spawns (classes 1-4) are shown in table I.

Classes 1 and 2 only concerned females that received the hormonal dose of $50 \mu \mathrm{g} \cdot \mathrm{kg}^{-1}$. Whatever the homogeneity class, $50 \mu \mathrm{g} \cdot \mathrm{kg}^{-1}$ stimulations led to poor quality spawns. These typical spawns can be described as follows using the dendrogram (figure 2): time of response to stimulation was short, large volumes of eggs were laid and eggs were small (particularly following second stimulation).

Spawns from classes 3 and 4 mainly came from females that were stimulated once or twice at stage B and with a dose of $20 \mu \mathrm{g} \cdot \mathrm{kg}^{-1}$ of LH-RHa, while ovarian homogeneity was poor $(\mathrm{OH}$ levels 1,2$)$. Class 3 mainly concerned second stimulations of stage B $(75 \%)$ and $\mathrm{C}(25 \%)$ females, with a quite high ovarian homogeneity (mainly $\mathrm{OH}$ level 2) and with a dose of $20 \mu \mathrm{g} \cdot \mathrm{kg}^{-1}$. Frequency of poor spawn results 
Table I. Characterization of individuals (ind.) belonging to classes 1 ( $n=3$ ind.), 2 ( $n=2$ ind.), 3 ( $n=6$ ind.), 4 ( $n=2$ ind.), 5 ( $n=5$ ind.), 6 ( $n$ $=6$ ind.), 7 ( $n=1$ ind.) and 8 ( $n=1$ ind.). Columns represent the characteristics of each individual at stimulation time: dose injected (Dose: 20 or $50 \mu \mathrm{g} \cdot \mathrm{kg}^{-1}$ ), number of stimulated spawning cycles (Nb Stimul; F: first induced spawning, S: second induced spawning), oocyte development stage (Stage; B or C), ovarian homogeneity level (OH; levels $1-3)$.

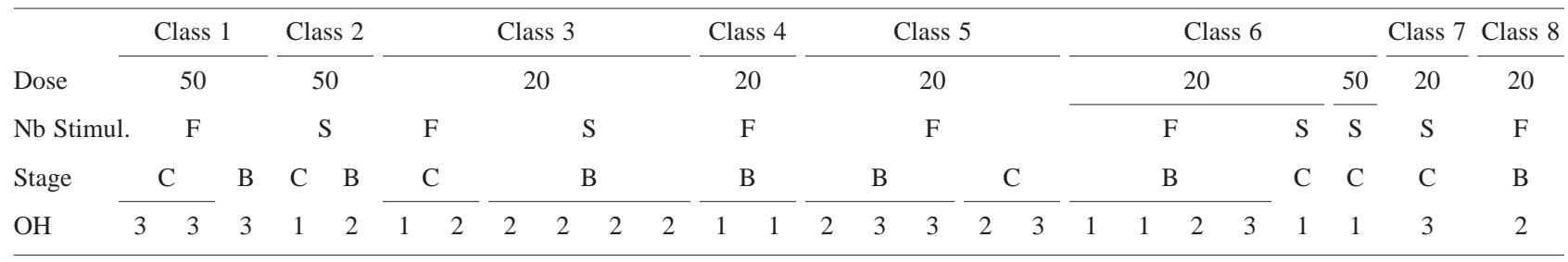

was higher for females injected at stage B when compared to animals treated at stage $\mathrm{C}$.

\subsubsection{Factors producing high quality spawn}

Table I also depicts classes 5-8 characterized by good spawn results, i.e. high fertilization, high proportion of eggs with a single oil droplet and low mortality for 6-day-old larvae. Levels 2 and 3 of ovarian homogeneity, whatever the oocyte development stage, and stage $\mathrm{C}$, particularly for second stimulation (classes 6 and 7), gave the best quality spawns.

\subsection{Influence of various factors upon spawning characteristics}

The study of factorial axis Eigenvalues showed that the first four axes of PCA accounted for $80 \%$ of the data variability. The factorial plane made up of axes 1 and 2 represented $54 \%$ of information, while each of factors 3 and 4 represented $13 \%$ of variability. The establishment of correlation circles indicated that plane 1-2 was well adapted to differentiate spawns, while planes $1-3,1-4,2-3$ and 2-4 could be discarded. Axis 1 is oriented by high quality spawn (negative values) and increasing mortality of larvae (positive values) while axis 2 is related to spawn size (positive values) and time of response to stimulation (negative values). The different variables describing egg quality were well correlated to factors 1 and 2. Their distribution in the correlation circle discriminated spawns using both quantitative and qualitative aspects and revealed the effects of different experimental conditions on egg quality (figure 3).

\subsubsection{Effect of the dose}

Individual spawns of females stimulated with either 20 or $50 \mu \mathrm{g} \cdot \mathrm{kg}^{-1} \mathrm{LH}-\mathrm{RHa}$ were represented by a spot on the factorial plane (figure 4). Spawns obtained after an injection of $50 \mu \mathrm{g} \cdot \mathrm{kg}^{-1} \mathrm{LH}-\mathrm{RHa}$ were isolated in the upper right quarter of the plane. Referring to the analysis proposed in figure 3, these spawns presented large volume and/or they were released following a short post-stimulation delay, but quality was poor. Mortality of larvae varied but was much higher than mean value. In spite of an important variability,

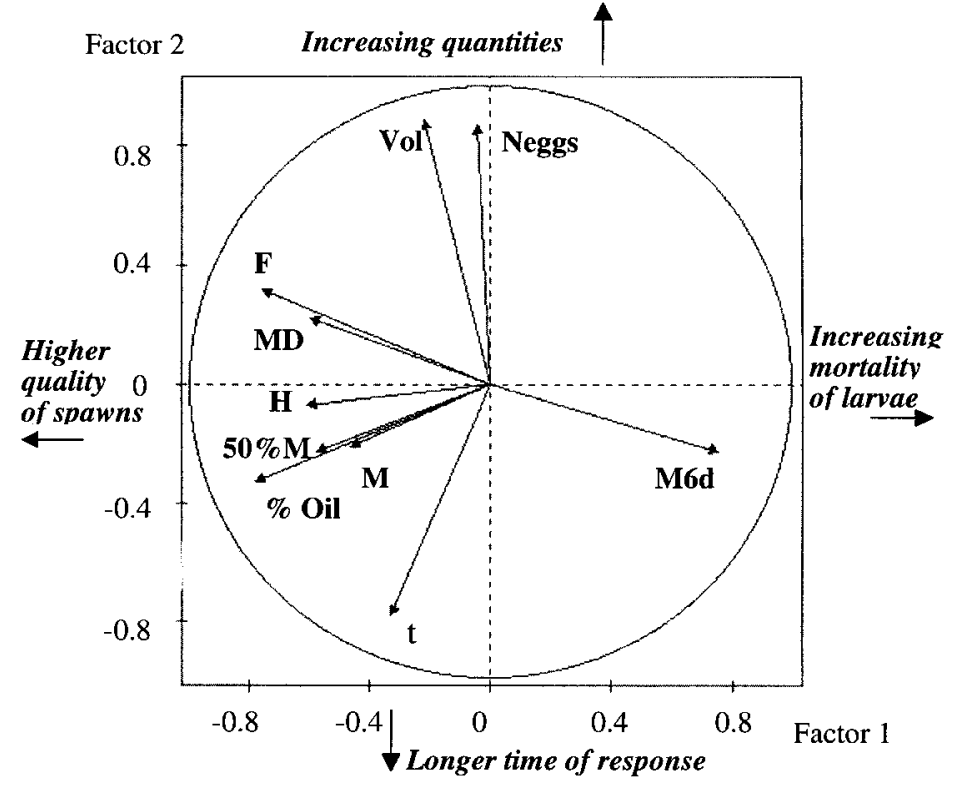

Figure 3. Correlation circle according to factors 1 and 2 (horizontal and vertical, respectively). Interpretation of the 'meaning' of principal component analysis 1-2 factorial plane is proposed in italics. t, time of response to stimulation; Vol, spawn volume; Neggs, number of eggs laid per spawn; \%Oil, percentage of eggs with a single oil droplet; $\mathrm{MD}$, mean diameter of eggs; $\mathrm{F}$, fertilization rate; $\mathrm{H}$, hatching rate; M6d, mortality rate after 6 days; $50 \% \mathrm{M}$, time of death of $50 \%$ of larvae; M, time of death of all starved larvae. 


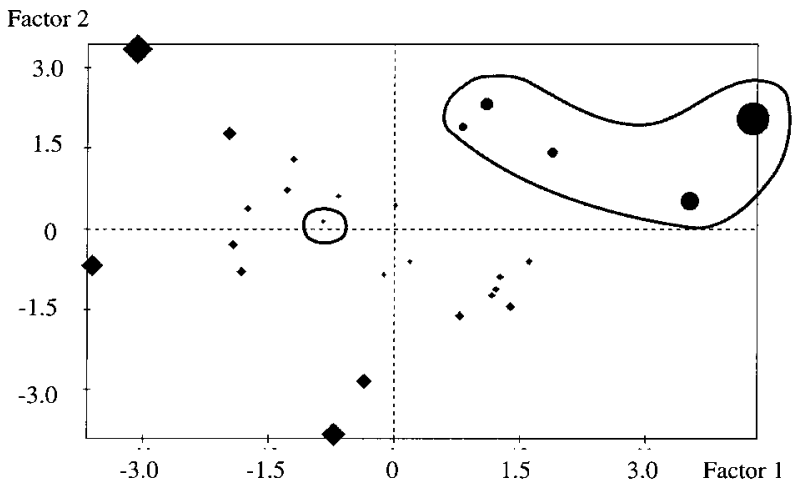

Figure 4. Comparison of individual spawns of females stimulated with either 20 (squares) or $50 \mu \mathrm{g} \cdot \mathrm{kg}^{-1}$ (circles) LH-RHa (size of the spots proportional to individual contribution).

spawns induced with $20 \mu \mathrm{g} \cdot \mathrm{kg}^{-1} \mathrm{LH}-\mathrm{RH}$ a were generally found on the left side of the plane indicating higher quality.

ANOVA revealed significant differences between doses for time of response, spawn volume, number of eggs produced, percentage of eggs with a single oil droplet and hatching (table II).

\subsubsection{Influence of ovarian state at stimulation time}

Figure 5 depicts spawns of females stimulated at stage B or stage C. Spawns are individually represented by a spot on the factorial plane. Individuals

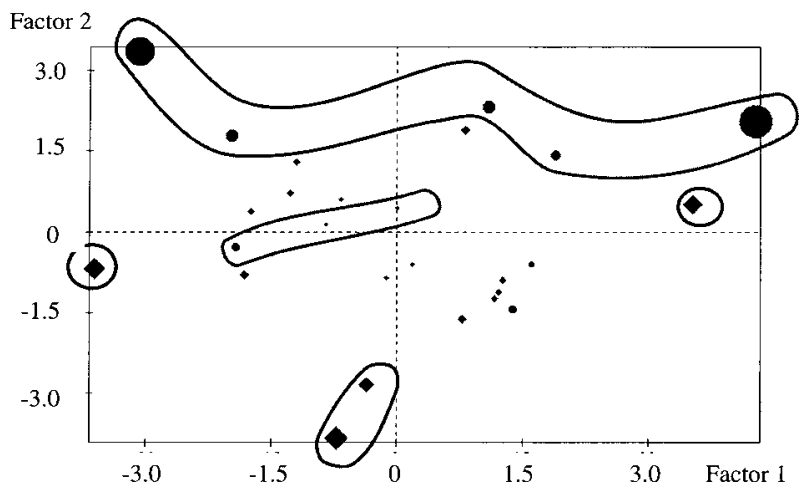

Figure 5. Comparison of individual spawns of females stimulated at the two post-vitellogenic oocyte stages chosen: stage B (squares) and stage $\mathrm{C}$ (circles) (size of the spots proportional to individual contribution).

stimulated at stage $\mathrm{C}$ were located among the positive values of factor 2 (higher volume of spawn and/or shorter time of response). However, since both populations were distributed along factor 1, ovarian state was not determinant for spawn quality.

ANOVA confirmed this conclusion showing only significantly higher number of eggs (table III) in spawns following stage $\mathrm{C}$ stimulation $(P<0.05)$.

Repartition of spawns issued from different ovarian homogeneity levels at stimulation time is shown in figure 6. Stimulation on high homogeneity ovaries

Table II. Mean $\left( \pm\right.$ SD) for the spawning results of females stimulated with doses of 20 and $50 \mu \mathrm{g} \cdot \mathrm{kg}^{-1} \mathrm{LH}-\mathrm{RHa}$. Values that share a common letter are not significantly different.

\begin{tabular}{|c|c|c|c|}
\hline Spawn features & $20 \mu \mathrm{g} \cdot \mathrm{kg}^{-1}(n=20$ females $)$ & $50 \mu \mathrm{g} \cdot \mathrm{kg}^{-1}(n=6$ females $)$ & \\
\hline Time of response (h) & $28 \pm 3^{\mathrm{a}}$ & $22.5 \pm 3^{\mathrm{b}}$ & $P<0.01$ \\
\hline Volume $(\mathrm{mL})$ & $420 \pm 229^{a}$ & $630 \pm 204^{\mathrm{b}}$ & $P<0.05$ \\
\hline Eggs laid (thousand) & $198.7 \pm 141^{\mathrm{a}}$ & $338.2 \pm 109.5^{\mathrm{b}}$ & $P<0.05$ \\
\hline Fertilization $(\%)$ & $30.2 \pm 29^{a}$ & $17.8 \pm 17.4^{\mathrm{a}}$ & \\
\hline Hatching $(\%)$ & $33 \pm 29.3^{\mathrm{a}}$ & $12.1 \pm 8^{\mathrm{a}}$ & \\
\hline Larval survival (day) & $5.2 \pm 4.3^{\mathrm{a}}$ & $2.9 \pm 4.1^{\mathrm{a}}$ & \\
\hline Larval mortality after 6 days $(\%)$ & $48.3 \pm 43.7^{\mathrm{a}}$ & $76.7 \pm 38.3^{\mathrm{a}}$ & \\
\hline Percentage of single oil droplet eggs & $88.4 \pm 9.3^{\mathrm{a}}$ & $62.8 \pm 15.4^{\mathrm{b}}$ & $P<0.01$ \\
\hline Egg diameter $(\mu \mathrm{m})$ & $856 \pm 29^{a}$ & $843 \pm 47^{\mathrm{a}}$ & \\
\hline
\end{tabular}

Table III. Mean $( \pm$ SD) for the spawning results of females stimulated at stages B and C. Values that share a common letter are not significantly different.

\begin{tabular}{lcc}
\hline Spawn features & Stage B $(n=16$ females $)$ & Stage C $(n=10$ females $)$ \\
\hline Time of response (h) & $28 \pm 4^{\mathrm{a}}$ & $26 \pm 3^{\mathrm{a}}$ \\
Volume (mL) & $406 \pm 215^{\mathrm{a}}$ & $569 \pm 247^{\mathrm{a}}$ \\
Eggs laid (thousand) & $177.6 \pm 88.3^{\mathrm{a}}$ & $316.2 \pm 180^{\mathrm{b}}$ \\
Fertilization (\%) & $22.8 \pm 24^{\mathrm{a}}$ & $34.6 \pm 31.1^{\mathrm{a}}$ \\
Hatching $(\%)$ & $28.3 \pm 24^{\mathrm{a}}$ & $27.9 \pm 27.8^{\mathrm{a}}$ \\
Larval survival (day) & $4.4 \pm 4.4^{\mathrm{a}}$ & $5.2 \pm 4.3^{\mathrm{a}}$ \\
Larval mortality after 6 days $(\%)$ & $56.2 \pm 45.6^{\mathrm{a}}$ & $52.8 \pm 42.4^{\mathrm{a}}$ \\
Percentage of single oil droplet eggs & $86.9 \pm 12.8^{\mathrm{a}}$ & $75.5 \pm 16.9^{\mathrm{a}}$ \\
Egg diameter $(\mu \mathrm{m})$ & $850 \pm 33^{\mathrm{a}}$ & $859 \pm 34^{\mathrm{a}}$ \\
\hline
\end{tabular}


(level 3) gave high quality spawns except for the values located in the top right quarter $\left(50 \mu \mathrm{g} \cdot \mathrm{kg}^{-1}\right.$ population). On the other hand, induction of females with heterogeneous gonads (level 1) led to intermediate or poorer results. Decreasing homogeneity lowered the probability of spawn showing high quality.

ANOVA of the three subpopulations of increasing homogeneity (levels 1, 2, 3) confirmed the preceding conclusions. Spawn volume, number of eggs, fertilization and mean diameter of eggs were significantly higher for level 3 compared to levels 1 and 2 which produced similar $(P>0.05)$ results (table $I V)$.

\subsubsection{Second stimulation potentialities}

Each individual spawn of females stimulated for the first time and for the second time (at least 15 days after the first treatment) is represented by a spot on the main factorial plane (figure 7). Distribution of spawns showed a diversity of response to both treatments on factors 1 and 2. The spread of individuals of the two subpopulations along the factor 2 axis did not allow conclusions concerning volume or response time. Distribution of individuals along the factor 1 axis reflected an influence of previous stimulation on newly induced spawn quality and larvae mortality: most spawns from first stimulation were shifted to negative values and second stimulation spawns were located in the positive region. However, this apparent quality decrease must be interpreted with care since both best and worst spawn results can be obtained following second stimulation. Comparison of responses to first and second hormonal stimulations by ANOVA (table $V$ ) showed only a significant difference for egg size $(P<0.05)$.

Comparison of responses to first and second stimulations at stage $\mathrm{B}$ and $\mathrm{C}$ separately provided further information (table VI). Significant differences were found between stage B first and second stimulations for egg size, fertilization, hatching, percentage of eggs with single oil droplet $(P<0.05)$ and larval survival $(P<0.01)$. In contrast, number of eggs, fertilization $(P<0.05)$ and larval survival $(P<0.01)$ were significantly lower for stage $\mathrm{B}$ second stimulation spawns than for stage $\mathrm{C}$ ones. Moreover, no significant difference was listed between stage $\mathrm{C}$ first and second stimulations.

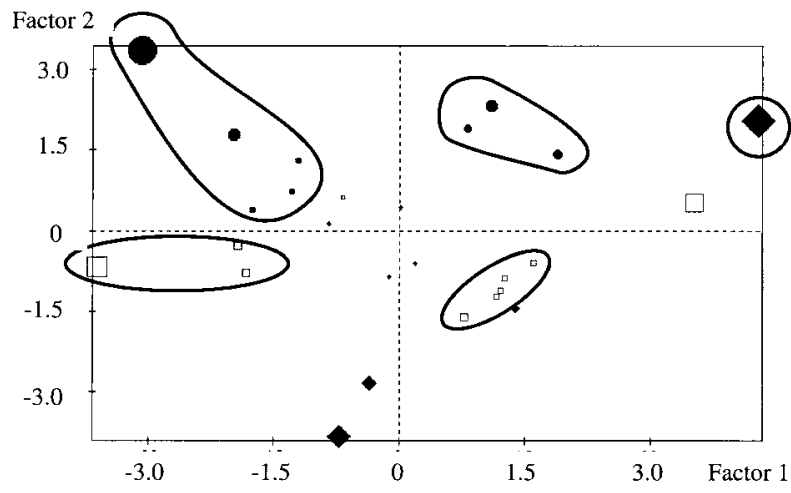

Figure 6. Comparison of individual spawns of females stimulated at different levels of increasing ovarian homogeneity: level 1 (full squares), level 2 (empty squares) and level 3 (circles) (size of the spots proportional to individual contribution).

\section{DISCUSSION}

\subsection{Method}

The use of combined analytical methods (PCA, HAC, ANOVA) proved to be helpful in evaluating the effects of different experimental treatments upon the quality of stimulated spawnings. It led to identification of links between different spawn features (variables), between individuals subjected to different treatments and to the establishment of spawn characteristics according to experimental treatments (link between variables and individuals).

Multivariate analysis methods allowed a different view of the experimental data since comparison of treatments could take account of data multifactorial variability. Indeed, multivariate methods such as principal component analysis represent upon the same factorial plane individuals characterized by the whole range of spawn features and analysis of individual dispersion provides global information about the characteristics of studied subpopulations. On the other hand, in one-way ANOVA two subpopulations of individuals are compared according to a particular spawn feature and comparison leads or fails to establish a significant difference between them. Several

Table IV. Mean $( \pm$ SD) for the spawning results of females stimulated with levels 1 and 3 of ovarian homogeneity. Values that share a common letter are not significantly different.

\begin{tabular}{lccc}
\hline Spawn features & Homogeneity $1(n=8$ females $)$ & Homogeneity $3(n=8$ females $)$ \\
\hline Volume (mL) & $320 \pm 169^{\mathrm{a}}$ & $758 \pm 161^{\mathrm{b}}$ & $345 \pm 151^{\mathrm{b}}$ \\
Eggs laid (thousand) & $182 \pm 166^{\mathrm{a}}$ & $46.3 \pm 27.7^{\mathrm{b}}$ & $P<0.05$ \\
Fertilization $(\%)$ & $12.6 \pm 12.5^{\mathrm{a}}$ & $28.4 \pm 24.6^{\mathrm{a}}$ & \\
Hatching (\%) & $21.6 \pm 19.7^{\mathrm{a}}$ & $5.4 \pm 4.2^{\mathrm{a}}$ & \\
Larval survival (day) & $5.3 \pm 4.2^{\mathrm{a}}$ & $46.1 \pm 44.8^{\mathrm{a}}$ & 8.05 \\
Larval mortality after 6 days $(\%)$ & $51 \pm 43^{\mathrm{a}}$ & $82.5 \pm 20.3^{\mathrm{a}}$ & \\
Percentage of single oil droplet eggs & $84.2 \pm 12.1^{\mathrm{a}}$ & $880 \pm 13^{\mathrm{b}}$ & $P<0.05$ \\
Egg diameter $(\mu \mathrm{m})$ & $847 \pm 33^{\mathrm{a}}$ & \\
\hline
\end{tabular}




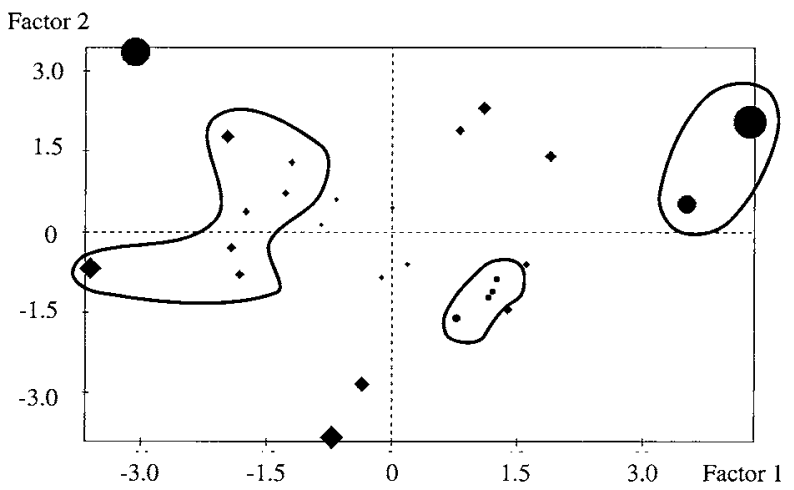

Figure 7. Comparison of first induced spawns (squares) and second induced spawns (circles) obtained following a new hormonal stimulation, at least 15 days after the first induced spawning cycle (size of the spots proportional to individual contribution).

successive comparisons of every feature and experimental treatment are necessary to analyse the population. As a consequence, the main difference between the two methods is the point of view on data information. When ANOVA focuses on a particular spawn feature, multivariate methods propose a global view taking account of all the parameters. As well, when
ANOVA provides simple binary results (there is or there is not a difference, with given probability), multivariate methods propose much more qualitative results and require interpretation of different documents (dendrogram and test values in HAC; correlation circle and factorial plane in PCA).

In the present work, HAC allowed a better understanding of the population structure. Incorporating test value study results into the dendrogram proved to be an easy way to provide a visual aid to explain the causes that separate the population into classes. Relation of initial conditions (characteristics at stimulation time) of all females to the classes to which they finally belong revealed the determinants of spawn quality and led to the establishment of spawn features that best differentiate between the results of different treatments. Then, PCA confirmed the former results of HAC concerning influence of dose, ovarian homogeneity, oocyte development and number of stimulated spawning cycles on spawn characteristics. These conclusions finally enabled us to choose those populations on which univariate analyses (ANOVA) could be performed and were supported by the significant differences listed by this last method.

Multivariate analysis proved to be an effective approach to egg quality. This was illustrated by factor

Table V. Mean $( \pm$ SD) for the spawning results of females receiving their first and second stimulations. Values that share a common letter are not significantly different.

\begin{tabular}{lcc}
\hline Spawn features & First $(n=17$ females $)$ & Second $(n=9$ females $)$ \\
\hline Time of response $(\mathrm{h})$ & $27 \pm 3^{\mathrm{a}}$ & $26 \pm 3^{\mathrm{a}}$ \\
Volume (mL) & $492 \pm 245^{\mathrm{a}}$ & $486 \pm 218^{\mathrm{a}}$ \\
Eggs laid (thousand) & $213 \pm 92.7^{\mathrm{a}}$ & $305 \pm 205^{\mathrm{a}}$ \\
Fertilization $(\%)$ & $34.2 \pm 26.1^{\mathrm{a}}$ & $20.3 \pm 27.5^{\mathrm{a}}$ \\
Hatching $(\%)$ & $34.3 \pm 29.2^{\mathrm{a}}$ & $22.2 \pm 22.9^{\mathrm{a}}$ \\
Larval survival (day) & $5.1 \pm 4.3^{\mathrm{a}}$ & $3.9 \pm 4.4^{\mathrm{a}}$ \\
Larval mortality after 6 days $(\%)$ & $45.8 \pm 43.9^{\mathrm{a}}$ & $62.5 \pm 42.4^{\mathrm{a}}$ \\
Percentage of single oil droplet eggs & $83.8 \pm 15.5^{\mathrm{a}}$ & $79.5 \pm 17.2^{\mathrm{a}}$ \\
Egg diameter $(\mu \mathrm{m})$ & $868 \pm 18^{\mathrm{a}}$ & $830 \pm 38^{\mathrm{b}}$ \\
\hline
\end{tabular}

Table VI. Mean $( \pm$ SD) for the spawning results of females receiving their first and their second stimulations at stages B and C.

\begin{tabular}{lcccc}
\hline Spawn features & \multicolumn{2}{c}{ Stage B } & \multicolumn{2}{c}{ Stage C } \\
\cline { 2 - 5 } & First $(n=11$ females $)$ & Second $(n=5$ females $)$ & First $(n=6$ females $)$ & Second $(n=4$ females $)$ \\
\hline Time of response (hour) & $28.3 \pm 4.5$ & $27 \pm 2.5$ & $25.6 \pm 3.4$ & $26.1 \pm 2.2$ \\
Volume (mL) & $430 \pm 244$ & $355 \pm 68$ & $539 \pm 243$ & $613 \pm 214$ \\
Eggs laid (thousand) & $179 \pm 97$ & $174 \pm 52$ & $243 \pm 88$ & $426 \pm 203^{* *}$ \\
Fertilization (\%) & $34.5 \pm 23$ & $5 \pm 7.9^{*}$ & $33.8 \pm 33$ & $35.7 \pm 32.8^{* *}$ \\
Hatching (\%) & $40.5 \pm 27.8$ & $10.4 \pm 14.2^{*}$ & $23.7 \pm 30.7$ & $34.1 \pm 25.5$ \\
Larval survival (day) & $6.3 \pm 3.9$ & 0 & $71.6 \pm 44.1$ & $8.8 \pm 0.7 * *$ \\
Larval mortality after 6 & $30 \pm 37.6$ & $0 *$ & $70.8 \pm 16.8$ & $24.5 \pm 19.7$ \\
days (\%) & $91.5 \pm 8$ & $76.6 \pm 19.8^{*}$ & $867 \pm 23$ & $82.5 \pm 16.6$ \\
Percentage of single oil & $868 \pm 15$ & $809 \pm 21^{*}$ & $846 \pm 41^{* *}$ \\
droplet eggs & & & \\
Egg diameter $(\mu \mathrm{m})$ & & &
\end{tabular}

* Significant differences between stage B first and second stimulations; ** significant differences between stage B and C second stimulations; $P<0.05$. 
1 of PCA which was correlated to a number of parameters (percentage of eggs with a single oil droplet, fertilization, larvae mortality, hatching, mean diameter of eggs) together leading to the identification of factor 1 negative values as an area of the factorial plane regrouping high quality spawn individuals. However, when analysed separately by ANOVA, these parameters often failed to describe the influence of the experimental treatments on egg quality [15] since they did not differ significantly between experiments.

\subsection{Biological application: LH-RHa influence on spawn quality of red drum}

The spawning stimulation and synchronization capacity of LH-RHa presented for other species was also verified for red drum. In the present work, 25 out of 26 hormonal stimulations induced spawning, whereas spontaneous spawnings were not observed among uninjected control females placed in the same environmental conditions. Hormonal stimulation influenced the final maturation process and particularly time of response, quantities of eggs released and spawn quality itself.

In the present experiment, high dose induction triggered maturation of a great number of oocytes, as illustrated by the quantities of eggs released, compared to lower dose, but egg quality evaluated by different features correlated to factor 1 decreased. However, the low dose of $20 \mu \mathrm{g} \cdot \mathrm{kg}^{-1}$ remains high compared to doses injected into other species [28] and could certainly be decreased.

Regarding egg quality, multivariate analyses led to the identification of the percentage of eggs with a single oil droplet as a quality indicator: this variable was of great importance for the discrimination of poor and high quality spawn classes in HAC (figure 2) and was highly correlated to negative values of factor 1 in the PCA correlation circle (figure 3). In the present work, oil droplet fractionation was higher for $50 \mu \mathrm{g} \cdot \mathrm{kg}^{-1}$ dose and stage B second stimulations. This is in agreement with Francescon et al. [11] who showed a strong correlation between LH-RHa dose and fractionation of oil droplet in sea bream. In red drum, the higher the fractionation is, the poorer the spawn quality, as was the case in sea bass [3, 10]. Reduced egg quality could be associated with disruption of the final maturation and ovulation process generated by LH-RHa injection [17].

\section{REFERENCES}

[1] Arnold C.R., Controlled year-round spawning of red drum (Sciaenops ocellatus) in captivity, Contrib. Mar. Sci. 30 (1988) 65-70.

[2] Brooks S., Tyler C.R., Sumpter J.P., Egg quality in fish: what makes a good egg?, Rev. Fish Biol. Fish. 7 (1997) 387-416.

[3] Carrillo M., Zanuy S., Prat F., Cerda J., Ramos J.,
Influence of the initial state (oocyte development stage and ovarian homogeneity, number of stimulations) on the quality of induced spawns was shown. Stage C hormonal injections led to significantly larger spawn than stage B. Such an influence was first noted by Weil [27]. Fauvel and Suquet [10] also reported this influence of oocyte development stage by showing that stage C treatment led to larger volumes of eggs and higher percentage of single oil droplet eggs than stage B. Ovarian homogeneity, quoted as the rough proportion of more developed oocytes among the total population of follicles in biopsies, appears as a novel method to examine the chance of success or failure of hormonal stimulation since the multivariate method revealed a relationship between spawn quality and this new parameter.

Hatching and larval survival contributed to egg quality assessment in multivariate analyses since they were correlated to factor 1 . However, despite the great diversity observed for these parameters, they did not differ significantly between treatments and failed to qualify as a stimulation effect in ANOVA.

\section{CONCLUSION}

Combination of multivariate and univariate methods, applied to different causes and effects upon a limited physiological event such as spawning proved to be efficient in the search for optimal conditions of hormonal stimulation. Multivariate analyses showed that egg quality was mainly described by proportion of eggs with a single oil droplet, fertilization, mortality of starved larvae after 6 days and by hatching or egg size in a less important way. However, it was not related to spawn volume or time of response to stimulation.

The main determinants for egg quality were decreasing LH-RHa dose, most developed oocyte state and increasing ovarian homogeneity.

Acknowledgements. We are particularly grateful to Marc Taquet (Ifremer, Martinique) for his advice and help with SPAD use, Pierre Dumont (Faune et Parcs, Canada) and the anonymous referees for reading and improving the paper, and the Regional Council of Martinique for financial support.

Mananos E., Bromage N., Seabass (Dicentrarchus labrax), in: Broodstock Management and Egg and Larval Quality, Blackwell Science, London, 1995, pp. $138-168$.

[4] Cibert C., Fermon Y., Vallod D., Meunier F.J., Morphological screening of carp Cyprinus carpio: relationship between morphology and fillet yield, Aquat. Living Resour. 12 (1999) 1-10.

[5] Corti M., Thorpe R.S., Sola L., Sbordoni V., Cataudella 
S., Multivariate morphometrics in aquaculture: A case study of six stocks of the common carp (Cyprinus carpio) from Italy, Can. J. Fish. Aquat. Sci. 45 (1988) 1548-1554.

[6] Crim L.W., Evans D.M., Vickery B.H., Manipulation of the seasonal reproductive cycle of the landlocked Atlantic salmon (Salmo salar) by LH-RH analogs administered at various stages of gonadal development, Can. J. Fish. Aquat. Sci. 4 (1983) 61-67.

[7] Dagnelie P., Théories et méthodes statistiques. Applications agronomiques. Vol. 2. Les méthodes de l'inférence statistique, Les Presses Agronomiques de Gembloux, Gembloux, 1975, 463 p.

[8] Donaldson E.M., Hunter G.A., Induced final maturation, ovulation, and spermiation in cultured fish, in: Hoar W.S., Randall D.J., Donaldson E.M. (Eds.), Fish Physiology, Vol. IX Part B, Academic Press, London, 1983, pp. 351-403.

[9] Escofier B., Pages J., Initiation aux traitements statistiques. Méthodes méthodologie, Presses Universitaires de Rennes, Rennes, 1997, 263 p.

[10] Fauvel C., Suquet M., La qualité des gamètes chez le bar et quelques déterminants en aquaculture, Piscic. Fr. 134 (1998) 5-10.

[11] Francescon A., Barbaro A., Colombo L., Bozzato G., Chiereghin S., Belvedere P., Induction of multiple spawning in the gilthead seabream (Sparus aurata) by LH-RH analogue treatments and their influence on egg quality, Riv. Ital. Acquacolt. 29 (1994) 109-120.

[12] Garcia L.M., Dose-dependent spaswning response of mature female sea bass, Lates calcarifer, to pelleted Luteinizing Hormon Releasing Hormon analogue (LH-RHa), Aquaculture 77 (1989) 85-96.

[13] Haraldsson H., Sveinsson T., Skulason S., Effects of LH-RHa treatments upon the timing of ovulation and upon egg and offspring quality in Arctic charr, Salvelinus alpinus, Aquac. Fish. Manage. 24 (1993) 145-150.

[14] Hopkins K.D., Pauly D., Instantaneous mortalities and multivariate models: Applications to tilapia culture in saline water, ICLARM Stud. Rev. 20 (1993) 105-111.

[15] Kjorsvik E., Mangor-Jensen A., Holmefjord I., Egg quality in fishes, Adv. Mar. Biol. 26 (1990) 71-113.

[16] Morineau A., Note sur la caractérisation statistique d'une classe par les valeurs tests, Bull. Cent. Int. Stat. Inform. Appl. 2-1 (1984) 20-27.

[17] Mylonas C.C., Hinshaw J.M., Sullivan C.V., GnRHainduced ovulation of brown trout (Salmo trutta) and its effects on egg quality, Aquaculture 106 (1992) 379-392.
[18] Nortvedt R., Brakstad F., Hansen T., Lunde T., Skybakmoen S., Kvalheim O.M., Multivariate approach to the study of fish growth, in: 2nd Scandinavian Symposium on Chemometrics (SSC2), Elsevier, Amsterdam, 1992, pp. 279-286.

[19] Parfouru D., Fauvel C., Développement ovocytaire chez l'ombrine (Sciaenops ocellatus) en conditions tropicales martiniquaises, Proc. Gulf Carrib. Fish. Inst. 50 (1999) 551-573

[20] Pauly D., Hopkins K.D., A method for the analysis of pond growth experiments, ICLARM Stud. Rev. 20 (1993) 199-203.

[21] Peter R.E., Lin H.R., Kraak G., Little M., Releasing hormones, dopamine antagonists and induced spawning, in: Muir J.F., Roberts R.J. (Eds.), Recent Advances in Aquaculture, Vol. 4, Blackwell Scientific Publications, Oxford, UK, 1993, pp. 25-30.

[22] Prein M., Hulata G., Pauly D., Multivariate Methods in Aquaculture Research: Case Studies of Tilapias in Experimental and Commercial Systems, ICLARM, Manila, 1993, 221 p.

[23] Roberts D.E., Photoperiod/Temperature control in the commercial production of red drum (Sciaenops ocellatus) eggs, in: Chamberlain G.W., Miget R.J., Haby M.G. (Eds.), Red Drum Aquaculture, Report, Texas Univ. Sea Grant Program, 1990, pp. 35-43.

[24] Thomas P., Boyd N.W., Induced spawing of spotted sea trout, red drum and orangemouth corvina (family: Scianidae) with Luteinizing Hormone-Releasing Hormone analog injection, Contrib. Mar. Sci. 30 (1988) 43-48.

[25] Thomas P., Arnold C.R., Holt G.J., Red drum and other sciaenids, in: Broodstock Management and Egg and Larval Quality, Blackwell Science Ltd, Oxford, 1995, pp. 118-137.

[26] Ward J.H., Hierarchical grouping to optimize and objective function, J. Am. Stat. Assoc. 58 (1963).

[27] Weil C., Billard R., Breton B., Jalabert B., Pituitary response to $\mathrm{LH}-\mathrm{RH}$ at different stages of gametogenesis in the rainbow trout (Salmo gairdneri), Ann. Biol. Anim. Biochim. Biophys. 18 (1978) 863-869.

[28] Zohar Y., Gonadotropin releasing hormone in spawning induction in teleosts: basic and applied considerations, in: Reproduction in Fish: Basic and Applied Aspects in Endocrinology and Genetics, INRA Press, Paris, 1988, pp. 47-62. 